This item was submitted to Loughborough's Research Repository by the author.

Items in Figshare are protected by copyright, with all rights reserved, unless otherwise indicated.

\title{
A comparative study between stirred dead end and circular flow in microfiltration of china clay suspension
}

PLEASE CITE THE PUBLISHED VERSION

http://dx.doi.org/10.2166/ws.2015.158

PUBLISHER

IWA Publishing

VERSION

AM (Accepted Manuscript)

\section{PUBLISHER STATEMENT}

This work is made available according to the conditions of the Creative Commons Attribution-NonCommercialNoDerivatives 4.0 International (CC BY-NC-ND 4.0) licence. Full details of this licence are available at: https://creativecommons.org/licenses/by-nc-nd/4.0/

\section{LICENCE}

CC BY-NC-ND 4.0

\section{REPOSITORY RECORD}

Shamsuddin, Norazanita, Chengcheng Cao, Victor Starov, and Diganta Bhusan Das. 2015. "A Comparative Study Between Stirred Dead End and Circular Flow in Microfiltration of China Clay Suspension". figshare. https://hdl.handle.net/2134/19479. 

of china clay suspension

\author{
*Corresponding author (Email: D.B.Das@lboro.ac.uk)
}

\title{
6 Abstract
}

7 A well-defined comparative study between stirred dead end and circular crossflow for 8 microfiltration of china clay suspension has been undertaken. The comparisons have been made

9 with respect to convective mass transfer coefficients, permeation and rejection rates, and energy 10 consumption. Similar operating and hydrodynamic conditions were implemented for the 11 comparison. According to our experimental data circular crossflow module was proven to 12 perform better as compared with the stirred dead end system due to the higher mass transfer 13 coefficients, higher permeation rates and lower energy consumption. The mass transfer 14 coefficients observed are comparable to previously found in vortex flow filtration and dead end 15 flow filtration. The presence of Dean vortices in circular crossflow module promotes flow 16 instabilities in the curved channel flow path which reduce concentration polarization effect during 17 the filtration process. The concentration polarization effect however deteriorated due to solute 18 build up (high solute concentration at the membrane surface) and decrease of the shear stress, 19 i.e., the particle lift forces on the membrane surface. This resulted in deposition of particles on 20 the membrane surface. In terms of energy consumption, for the same energy cost the limiting 21 flux reached in circular crossflow is found higher than in stirred dead end unit.

22 Keywords: Circular crossflow - Stirred dead end - Shear stress - Dean vortices 23 Microfiltration - Mass transfer coefficient

\section{Introduction}

25 Microfiltration (MF) is regarded as one of the oldest separation techniques among the pressure26 driven membrane separation processes (Strathmann et al., 2011). Both MF and ultrafiltration 27 (UF) membranes have been used extensively for the removal of particles, turbidity and 28 microorganisms for water treatment (Gray et al., 2011; Shamsuddin et al., 2014). However, 29 membrane fouling is a major impediment to membrane efficiency and it results in the reduction 30 of membrane performance (Kochkodan et al., 2014; Guo et al., 2012; Gao et al., 2011). Despite 31 the vast efforts to reduce the effect of membrane fouling by improving membrane properties, 32 optimizing operating conditions and pre-treatment of feed water, fouling is unavoidable (Costa et 33 al., 2006). Improved hydrodynamic conditions such as manipulating shear rates on membrane 
surfaces, improved design of the membrane modules, and induced flow instabilities are other useful methods in overcoming membrane fouling and concentration polarization (Jaffrin, 2012).

36 Researchers have discussed various ways to induce these flow instabilities such as Taylor (Park et al., 1994; Belfort et al., 1993; Kroner and Nissinen, 1988) and Dean vortices (Kaur and Agarwal, 2002; Manno et al., 1998; Nunge and Adams, 1971; Srinivasan and Tien, 1971). Taylor vortices, which are resulted from rotating annular filter, was found to be one the most succesful techniques in reducing concentration polarization effects and membrane fouling. Both vortices

41 have similarities in principles and use centrifugal forces to give rise to secondary flows which

42 disrupt solute build-up on membrane surfaces, thus reducing concentration polarization and 43 increasing permeation rates. However, Taylor vortices require substantially more energy than 44 stationary Dean vortices. Hence, Taylor vortices have limited potential for upscaling as 45 compared to Dean vortices. Experimental investigations undertaken by Belfort and his co46 workers (1993-1997) proved that Dean vortices effectively improve membrane filtration 47 performances using curved channel modules. Kaur and Agarwal (2002) was the first to the best 48 of our knowledge, who studied the effects of Dean vortices on filtration performance involving 49 ultrafiltration of protein suspensions in circular thin flow channel module. They have 50 experimentally calculated the mass transfer coefficients which were found to be higher than 51 classical filtration models by a factor 7-10.

52 The objective of this paper is to study the effects of Dean vortices on reducing concentration 53 polarization and membrane fouling, and an increase of permeation fluxes in the case of MF of 54 china clay suspensions through the study of hydrodynamics. While a significant amount of research has been done for reverse osmosis (RO) and UF which were widely used for desalination and removal of natural organic matter, MF for china clay particles draws less attention. Also, little research has been done for the influence of membrane configurations on the filtration performance. Thus, in this study, a comparison between circular crossflow and stirred dead end flow is attempted. Hydrodynamic condition such as shear stress on membrane wall which determined the mass transfer coefficients of particles needs to be investigated as

61 Becht et al. (2008) explained it is essential to define hydrodynamic conditions in much detail 62 without leaving out the importance similar operating conditions during comparison experiments. 63 Hence, the aim of this paper is to investigate the hydrodynamic conditions of the two set-ups, i.e. 64 circular crossflow and stirred dead end flow using china clay suspension as contaminant, and 65 MF membranes for filtration processes as detailed below.

\section{Experimental Procedure}

2.1. Materials

68 Microfiltration experiments were performed with mixed cellulose ester membrane (GSWP09000) 69 consisting of cellulose acetate and cellulose nitrate which has an average pore size of $0.22 \mu \mathrm{m}$ 
70 (Merck Millipore, Darmstadt, Germany). According to the manufacturer, the membranes are 71 hydrophilic with thickness and porosity of $150 \mu \mathrm{m}$ and $75 \%$, respectively. A view of the clean 72 membrane sample pictured using scanning electron microscope (SEM) is shown in Figure 1 (a).

73 The particle size distribution of clay particles (Sigma-Aldrich, Dorset, UK) was evaluated using

74 Malvern-Sizer laser light scattering instrument (Malvern Instruments, Malvern, UK) and the result 75 is shown in Figure 1 (b).
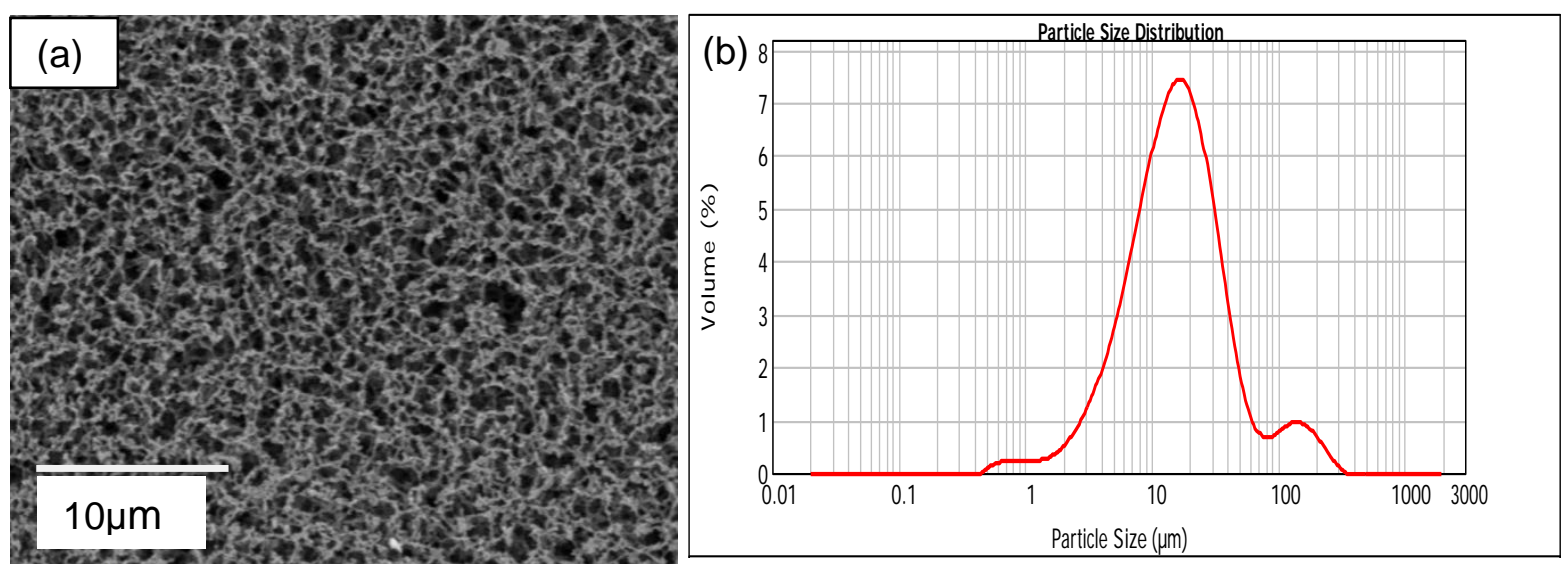

Figure 1 (a) membrane sample of $0.22 \mu \mathrm{m}$ mixed cellulose ester, (b) Particle size distribution of

78 clay particles.

\subsection{Preparation of sample filtration}

80 Prior to filtration experiments, the membrane was soaked in deionized water for 1 hour with 81 water changing every 20 minutes in order to remove any wetting agents. Measurement of pure 82 water fluxes for each clean membrane was carried out. The ionic strength was adjusted to $830.01 \mathrm{M}(0.585 \mathrm{~g} / \mathrm{l})$ by adding sodium chloride $(\mathrm{NaCl})$, purchased from Sigma-Aldrich (Dorset, UK), 84 into the china clay suspensions. In order to produce a homogeneous mixture the suspension 85 was placed priory to the experiments in an ultrasonic water bath for approx. 30 minutes at 86 temperature of $22 \pm 2^{\circ} \mathrm{C}$. The $\mathrm{pH}$ of the china clay suspensions was adjusted to the selected $\mathrm{pH}$ 87 values by adding various amount of hydrochloric acid $(\mathrm{HCl})$ or sodium hydroxide $(\mathrm{NaOH})$, which 88 were bought from Sigma-Aldrich (Dorset, UK) into the suspensions. The turbidity of the prepared 89 suspensions was measured by a turbidity meter (model 20000; HF Scientific, Fort Myers, USA). 


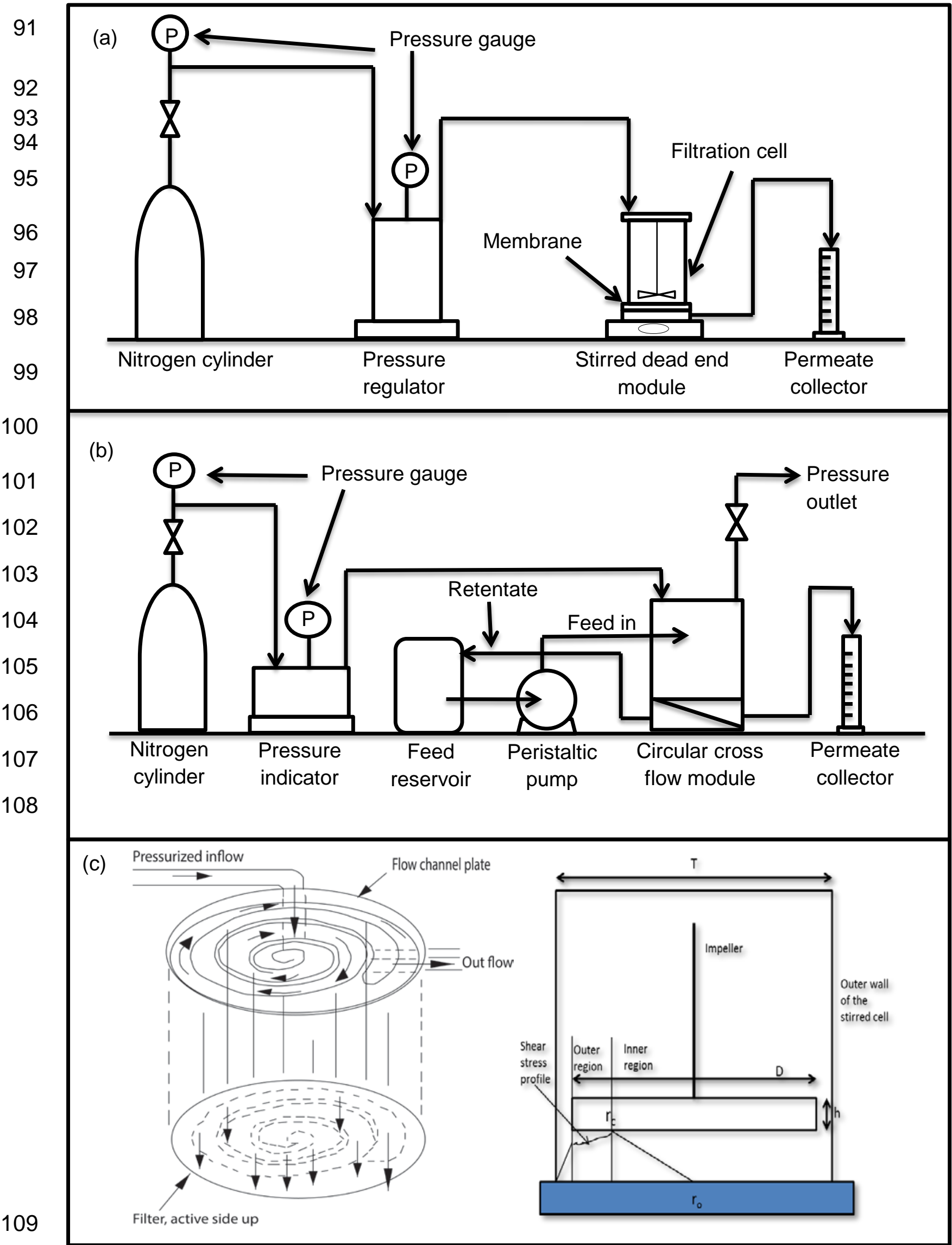

110 Figure 2 Schematic diagrams of filtration apparatus with (a) stirred dead end module, (b) circular

111 crossflow module, and (c) side views of circular crossflow cell and stirred dead end flow 112 respectively. 
114 For the comparison of experiments two different configurations were used. Circular crossflow

115 module manufactured by Amicon (Massachusetts, USA) and stirred dead end apparatus (model 116 XFUF07601) purchased from Merck Millipore (Darmstadt, Germany).

117 A schematic of the experimental set up is shown in Figure 2. The stirred dead end system 118 (Figure 2 (a) and (c)) has a fixed volume of $300 \mathrm{ml}$. The cell has an effective filtration surface 119 area of $40 \mathrm{~cm}^{2}$ with diameter of $76 \mathrm{~mm}$. The feed reservoir was agitated by a flat blade paddle 120 impeller (65 $\mathrm{mm}$ diameter and $9 \mathrm{~mm}$ height). Prior to filtration experiments the feed suspension 121 was added into the feed reservoir. The membrane was placed at the bottom of the filtration cell 122 while the pressure from nitrogen cylinder was monitored by a pressure gauge and controlled by 123 a pressure regulator (model 8286; Porter Instrument Co., Hatfield, USA). The speed of the flat 124 blade paddle impeller was measured using a digital tachometer (Shenzhen Ever Good 125 Electronic Co Ltd, Shenzhen, China).

126 Figure 2 (b) - (c) shows circular crossflow module with inside view of the filtration cell. The 127 module has a feed volume of $600 \mathrm{ml}$ and $40 \mathrm{~cm}^{2}$ effective filtration surface areas. Both the feed 128 and the retentate were recycled back into the feed reservoir at room temperature in order to 129 maintain a constant suspension concentration throughout the filtration experiment. Figure 2 (c) 130 shows a flow pattern of the suspension in a circular channel over the membrane surface. There 131 were three spirals with radii from $1 \mathrm{~cm}$ to $4.1 \mathrm{~cm}$, with channel spacing of approximately $1 \mathrm{~cm}$. 132 The spiral channel has the following specs: length $(760 \mathrm{~mm})$, width $(9.5 \mathrm{~mm})$ and height $(0.38$ $133 \mathrm{~mm}$ ) according to the manufacturer. The feed reservoir was pressurized by nitrogen which was 134 adjusted to a predetermined pressure using manually operated valves. Pressure indicator was 135 used to monitor pressure inside the feed vessel. Calibration of pressure gauges was conducted 136 for both modules by validating the gauges with precise gauge at changing pressures values. A 137 new clean membrane was used and pre-treated for every new set of experiment. All 138 experiments were carried out at room temperature $\left(22^{\circ} \mathrm{C} \pm 2^{\circ} \mathrm{C}\right)$. Permeate collection was made 139 at 1 min intervals.

\section{3. Theory}

141 In the circular flow module the difference in pressures between internal and external walls of the 142 circular channel flow gives rise to secondary flows known as Dean vortices. This phenomenon 143 was shown to exist in such module above a critical Reynolds number (Kaur and Agarwal, 2002). 144 Equation (1) can be used to calculate Dean number in the curved channel (Dean, 1928):

$145 D e=R e_{C F} \sqrt{\frac{d_{i}}{d_{c}}}$,

146 where $R e_{C F}$ is the Re number above critical Re (approx. 33-45), which was found experimentally 147 by Brewster et al. (1959); $d_{i}$ is the equivalent hydraulic diameter calculated to be $0.0745 \mathrm{~cm}$; and 
$148 d_{c}$ is the diameter of curvature of the channel path has been calculated to be $4.51 \mathrm{~cm}$.

149 As mentioned earlier, it is essential to have similar operating conditions for comparison but one 150 must not leave out the importance of hydrodynamic conditions in order to satisfy the purpose of 151 comparison. Therefore the calculation of shear stress in circular flow system was made 152 according to Becht et al. (2008), i.e., by solving the force balance aross the membrane:

$153 \tau_{C F}=\frac{\Delta P d_{i}}{4 L}$

154 where $\Delta P$ is the transmembrane pressure, and $L=760 \mathrm{~mm}$ is the length of the membrane 155 channel. A predetermined filtration pressure of 0.1 bar with cross flow velocity of $1.156 \mathrm{~m} / \mathrm{s}$ 156 resulted a flow profile pattern which corresponds to the Reynolds number of 867 and a shear 157 stress approx. 1.27 Pa.

158 However, similar calculation for the case of stirred dead end filtration is not straight forward. 159 According to Kosvintev et al. (2005) the filtration cell has to be divided into two regions i.e. inner 160 region and outer region. At the critical radius of the flat blade paddle impeller, the shear stress is 161 the highest but then decreases as it reaches the outer region. Therefore, in order to calculate the 162 shear stress across the whole membrane, an average value of both the inner and outer regions 163 should be calculated. Kosvintsev et al. (2005) developed the following correlation to find the 164 critical radius:

$165 r_{c}=\frac{D_{i}}{2} 1.23\left(0.57+0.35 \frac{D_{i}}{D_{t}}\right) \times\left(\frac{h}{D_{t}}\right)^{0.036} n_{b}{ }^{0.116} \frac{R e_{i}}{1000+1.43 R e_{i}}$,

166 where $D_{i}$ is the diameter of flat blade paddle impeller, $D_{t}$ is the diameter of the filtration cell, $h$ is 167 the height of the flat blade paddle impeller, $R e_{i}$ is the Reynolds number for the flat blade paddle 168 impeller, and $n_{b}$ is the number of flat blade paddle impeller used.

169 The Reynolds number for both modules i.e. circular crossflow and stirred dead end can be 170 calculated using Equations (4) and (5) respectively:

$171 R e_{C F}=\frac{\rho u d_{i}}{\mu}$,

$172 R e_{D E}=\frac{\rho \omega r_{t}^{2}}{\mu}$,

173 where $\mu$ is the dynamic viscosity of the fluid, $\rho$ is the density of the fluid, $r_{t}$ is the radius of the 174 filtration cell, and $\omega$ is the angular velocity. Equation (5) was also used to calculate $R e_{i}$.

175 Shear stresses on the inner and outer regions are given by Equations (6) and (7) respectively:

$176 \tau_{i}=0.825 \mu \omega r \frac{1}{\delta} ; \quad$ for $r<r_{c}$, 
$177 \tau_{o}=0.825 \mu \omega r_{c}\left(\frac{r_{c}}{r}\right)^{0.6} \frac{1}{\delta} ; \quad$ for $r>r_{c}$

178 where $\delta$ is the momentum boundary layer $\left(\delta=\sqrt{\frac{\mu}{\rho \omega}}\right)$.

179 The stirred dead end module has a critical radius of $2.37 \mathrm{~cm}$. In order for the system to achieve 180 a similar shear stress as in the circular flow module, the flat blade paddle impeller requires 181 rotation speed of $145 \mathrm{rpm}$, which equals to the shear stress of $1.27 \mathrm{~Pa}$.

182 Cussler (2009) defined mass transfer coefficient as resistance to diffusion rate constant for 183 solute movement in boundary layer at the solid and liquid interface. Mass transfer coefficeint 184 was calculated according to the concentration polarization model proposed by Zydney and 185 Colton (1986), Colton et al. (1975), and Blatt et al. (1970). Diffusion coefficient (D) is defined as 186 the ratio of molar flux and the driving force, and determined by the Stokes-Einstein (Einstein, 187 1905):

$188 \mathrm{D}=\frac{k_{B} T}{6 \pi \mu r_{s}}$,

189 where $k_{B}$ is Boltzmann constant $\left(1.38 \times 10^{-23} \mathrm{~m}^{2} \mathrm{~kg} \mathrm{~s}^{-2} \mathrm{~K}^{-1}\right), T$ is the operating temperature in 190 Kelvin, and $r_{S}$ is the average radius of china clay particles. Hence, the diffusion coefficient $D$ 191 according to Equation 8 was found to be $2.755 \times 10^{-14} \mathrm{~m}^{2} / \mathrm{s}$.

192 The theory for calculation the mass transfer coefficient for the circular crossflow was explained 193 elsewhere (see e.g., Kaur and Agarwal, 2002). The following Sherwood correlation was 194 developed from our experimental results to describe the mass transfer coefficient for circular 195 crossflow module i.e. mass transfer of solutes from membrane interface into the bulk phasae, $k_{m}$ :

$196 S h=2.61 D e^{1.02} S c^{0.33}$,

197 where $S c$ is the Schmidt number which is the ratio of viscous diffusion rate and molecular 198 diffusion rate $\left(\mathrm{Sc}=\frac{\mu}{\rho D}\right)$.

199 The mass transfer coefficient for the stirred dead end system can be obtained from the typical 200 mass transfer correlations. The mass transfer coefficient, $k_{n}$, in the stirred dead end cell was 201 obtained from the following Sherwood, Sh, correlation (Mehta and Zydney, 2006):

$202\left(\frac{k_{n} r_{t}}{D}\right)=S h=0.27 R e_{d}^{0.567} S c^{0.33}$ 


\section{Results and Discussions}

\subsection{Comparison of circular crossflow module and stirred dead end module}

\subsubsection{Filtration performance}

206 Pure water fluxes of six clean cellulose ester membrane samples were measured for the 207 investigation of hydraulic membrane resistance under constant transmembrane pressure of 208 0.05bar for both circular crossflow system and stirred dead end system. Figure 3 illustrates total 209 hydraulic resistances of membranes for both modules. The flux can be related to the total 210 hydraulic resistance according to Darcy's law. Pure water fluxes measurement in circular 211 crossflow system (ranges between 550-650 l/ $/ \mathrm{hr}^{\mathrm{m}} \mathrm{m}^{2}$ ) are much higher than that in stirred dead 212 end system of approx. $120 \mathrm{l} / \mathrm{hr} \cdot \mathrm{m}^{2}$. Hydraulic resistance has an inversely proportional 213 relationship with flux according to the following equation:

$214 J=\frac{\Delta P}{\mu R_{\text {tot }}}$

215 where $J$ is the permeate flux $\left(\mathrm{m}^{3} / \mathrm{m}^{2} s\right), \Delta P$ is transmembrane pressure $(P a), \mu$ is the dynamic 216 viscosity (Pa.s), and $R_{\text {tot }}$ is the total hydraulic resistance $\left(m^{-1}\right)$.

217 The differences in total hydraulic resistances for both modules are shown in Figure 3. Total 218 hydraulic resistance in the circular flow module are much lower than in the stirred dead end. This 219 is attributed to the effect of Dean vortices in the circular crossflow module. The flow pattern 220 changes from typical laminar flow into an unstable laminar flow called Dean vortices when a fluid 221 flows in the curved channel path at Reynolds number above the critical Reynolds number. As a 222 result of flow instabilities the resistance becomes lower according to Winzeler and Belfort (1999). 223 The absence of such flow instabilities in stirred dead end results in much higher hydraulic 224 resistance. 


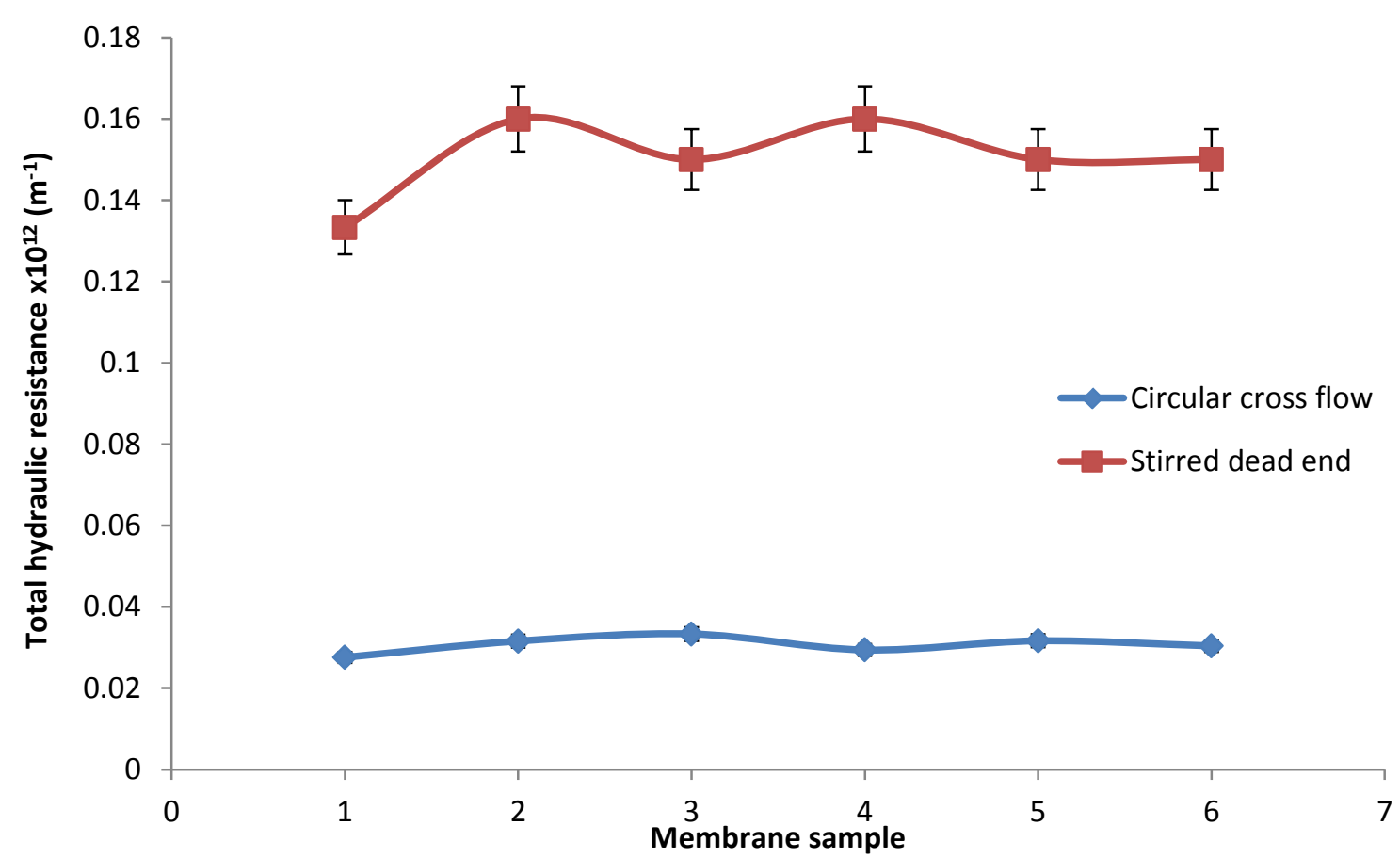

Figure 3 Total hydraulic resistances provided by membrane samples for circular crossflow 228 module and stirred dead end module.

229 All filtration experiments were carried out with suspension concentration $(0.4 \mathrm{~g} / \mathrm{l})$, ionic strength $230(0.01 \mathrm{M})$ and the filtration pressures (0.1bar and 0.05 bar, respectively) for direct comparison 231 between the circular flow module and stirred dead end module The flow profile of circular flow is 232 laminar which corresponds to the Reynolds number of 867 according to Equation (4). The cross233 flow velocity has been calculated as $1.156 \mathrm{~m} / \mathrm{s}$. Reynolds number of the stirred dead end system 234 was found 21,352 (turbulent flow) using Equation (5). Instead of keeping the Reynolds number 235 uniform for both systems, the shear stresses on top of the membranes were made equal in order 236 to maintain the entire operating conditions consistent for comparison. Equations (2) - (7) were 237 used to calculate the shear stresses for both modules which were equal to 1.27 Pa.

239 Limiting flux for circular crossflow is six times greater than for stirred dead end (Figure 4). After 24025 minutes the flux varied within $\pm 5 \%$, hence, a steady state value was reached in the case of 241 circular crossflow module. A steady state flux was also reached in the case for stirred dead end 242 module, however, much faster (less than in 10 minutes) and much lower value (Figure 4). This is 243 attributed to the presence of Dean vortices effect in circular crossflow, which depolarized solute 244 build-up near the membrane interface: due to the higher wall shear stress particle were removed 245 from the membrane surface. This resulted in an intensive mixing between the boundary layer 246 and the bulk phase (Bubolz et al., 2002). The formation of Dean vortices in circular flow module 247 slowed down formation of the steady state accumulation of solutes on membrane surface in the 248 early stage of the filtration process. Hence, the presence of Dean vortices results in 249 improvement of mass transfer of solute from the membrane surface into the bulk solution. 


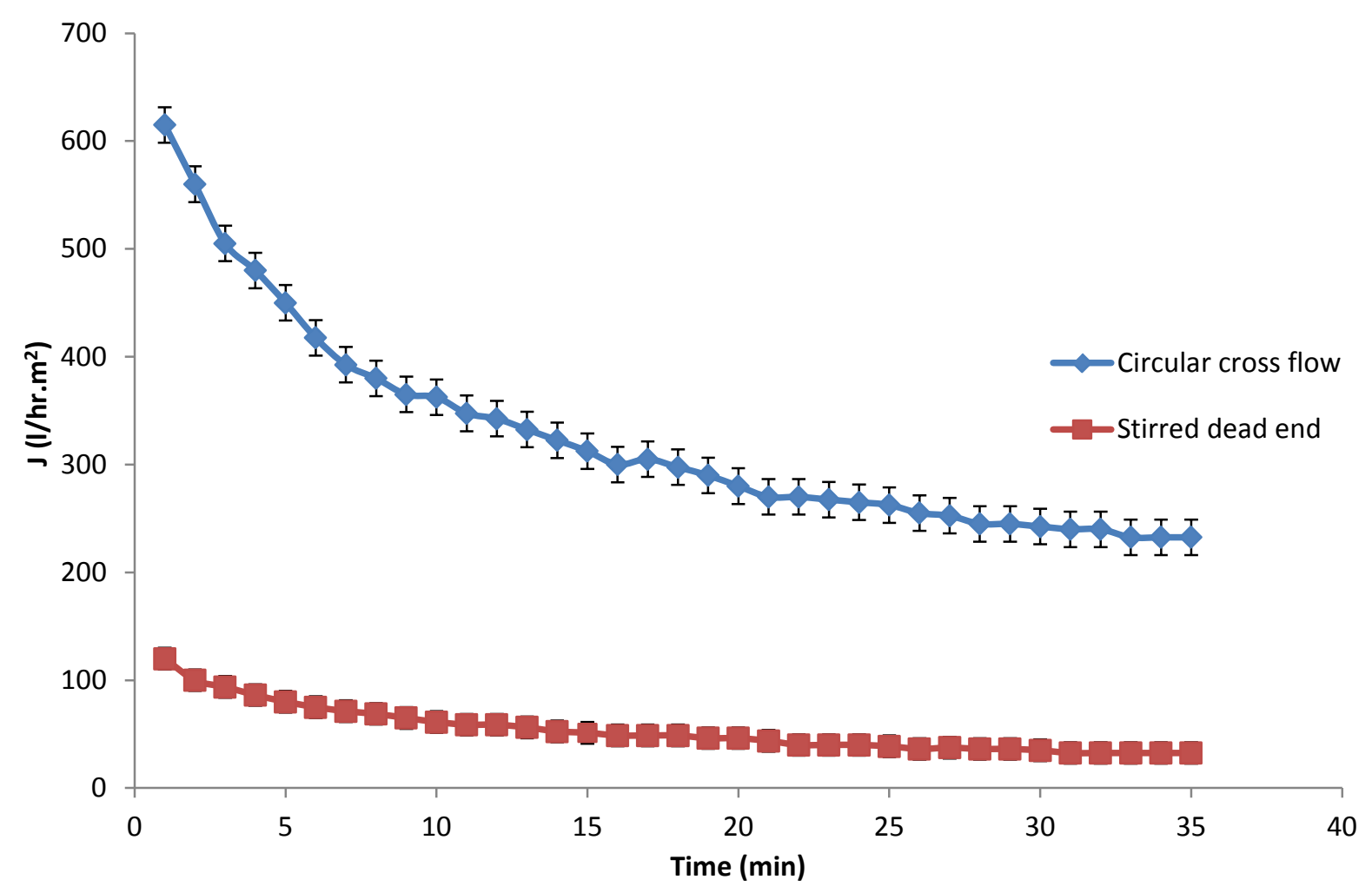

Figure 4 Permeate fluxes for circular crossflow module and stirred dead end module.

\subsubsection{Mass transfer coefficients}

253 The mass transfer coefficients calculated for circular crossflow system are in the range between

$2541.19 \times 10^{-6} \mathrm{~m} / \mathrm{s}$ and $3.66 \times 10^{-6} \mathrm{~m} / \mathrm{s}$ calculated according to Equation (9). The mass transfer 255 coefficients for stirred dead end system are calculated according to Equation (10) and are found 256 in the range between $1.12 \times 10^{-7} \mathrm{~m} / \mathrm{s}$ and $4.31 \times 10^{-8} \mathrm{~m} / \mathrm{s}$. According to Muller et al. (2003) for 257 dead end filtration typical mass transfer coefficients were found about $5 \times 10^{-8} \mathrm{~m} / \mathrm{s}$, whereas for 258 cross flow filtration $1 \times 10^{-6} \mathrm{~m} / \mathrm{s}$ to $5 \times 10^{-6} \mathrm{~m} / \mathrm{s}$, and for vortex flow filtration $0.5 \times 10^{-5} \mathrm{~m} / \mathrm{s}$ to $4 \times$ $25910^{-5} \mathrm{~m} / \mathrm{s}$. Hence, from our results the mass transfer coefficients for circular crossflow were 260 comparable with those obtained for vortex flow filtration. We concluded that it was due to the 261 presence of Dean vortices in the circular crossflow that resulted in improved mass transfer 262 coeffficient. Circular crossflow module showed better performance than stirred dead end module 263 as shown in Figures 3 and 4 at similar operating and hydrodynamic conditions. In stirred dead 264 end module the absence of such vortices led to a rapid build-up of solutes on membrane surface 265 thus concentration polarisation effect took place. Although there was a stirrer to minimize the 266 solute build-up it still could not reduce the concentration polarization effect as filtration process 267 progressed. 
270 Table 1 Observed rejection coefficient for circular crossflow and stirred dead end modules.

\begin{tabular}{llll}
\hline Configuration & $\begin{array}{l}\text { Permeate turbidity } \\
(\mathrm{NTU})\end{array}$ & $\begin{array}{l}\text { Clay concentration in } \\
\text { permeate }(\mathbf{g} / \mathbf{l})\end{array}$ & $\begin{array}{l}\text { Observed } \\
\text { Rejection } \\
\text { coefficient }\end{array}$ \\
\hline $\begin{array}{l}\text { Circular } \\
\text { crossflow }\end{array}$ & $0.35 \pm 0.04$ & $0.001302 \pm 0.05$ & $0.996744 \pm 0$. \\
Stirred dead end & $0.91 \pm 0.06$ & $0.003317 \pm 0.05$ & 06 \\
& & & $0.991708 \pm 0$. \\
\hline
\end{tabular}

271

272 Observed rejection coefficients were found to be close to one according to Table 1 . The true or

273 actual rejection percentage can be calculated using the following formula using the film model

274 for concentration polarization (Blatt et al., 1970):

$275 \quad R_{t r}=\frac{R_{o b s}}{\left(1-R_{o b s} / \exp (J / k)+R_{o b s}\right.}$.

276 As filtration process progressed, the observed rejection coefficients changes very slightly and lie

277 within 3\% to $6 \%$ variation as shown in Table 1. The true rejection percentages were calculated

278 for both modules which were close to one. High solute concentration near the membrane

279 surface led to the diffusion of the solute component in the opposite direction i.e. to the bulk.

280 Therefore, concentration polarization did take place on membrane surface but more severe in

281 the case for stirred dead end module as seen in Figure 4. The reason why such phenomenon

282 took place in circular crossflow module was because of lower wall shear stress of $1.27 \mathrm{~Pa}$ and

283 concentration of solute used was high ( $0.4 \mathrm{~g} / \mathrm{l})$. This resulted in a decreasing influence of effect

284 of Dean vortices as filtration progressed because due to rapid solute build up and shear stress

285 decreased the particle lift forces thus resulting in a deposition of solutes on the membrane

286 surface. Therefore, it would be very important to search for the optimum operating and

287 hydrodynamic conditions, i.e. higher wall shear stress (high operating pressure) and lower solute

288 concentration might be desirable. 


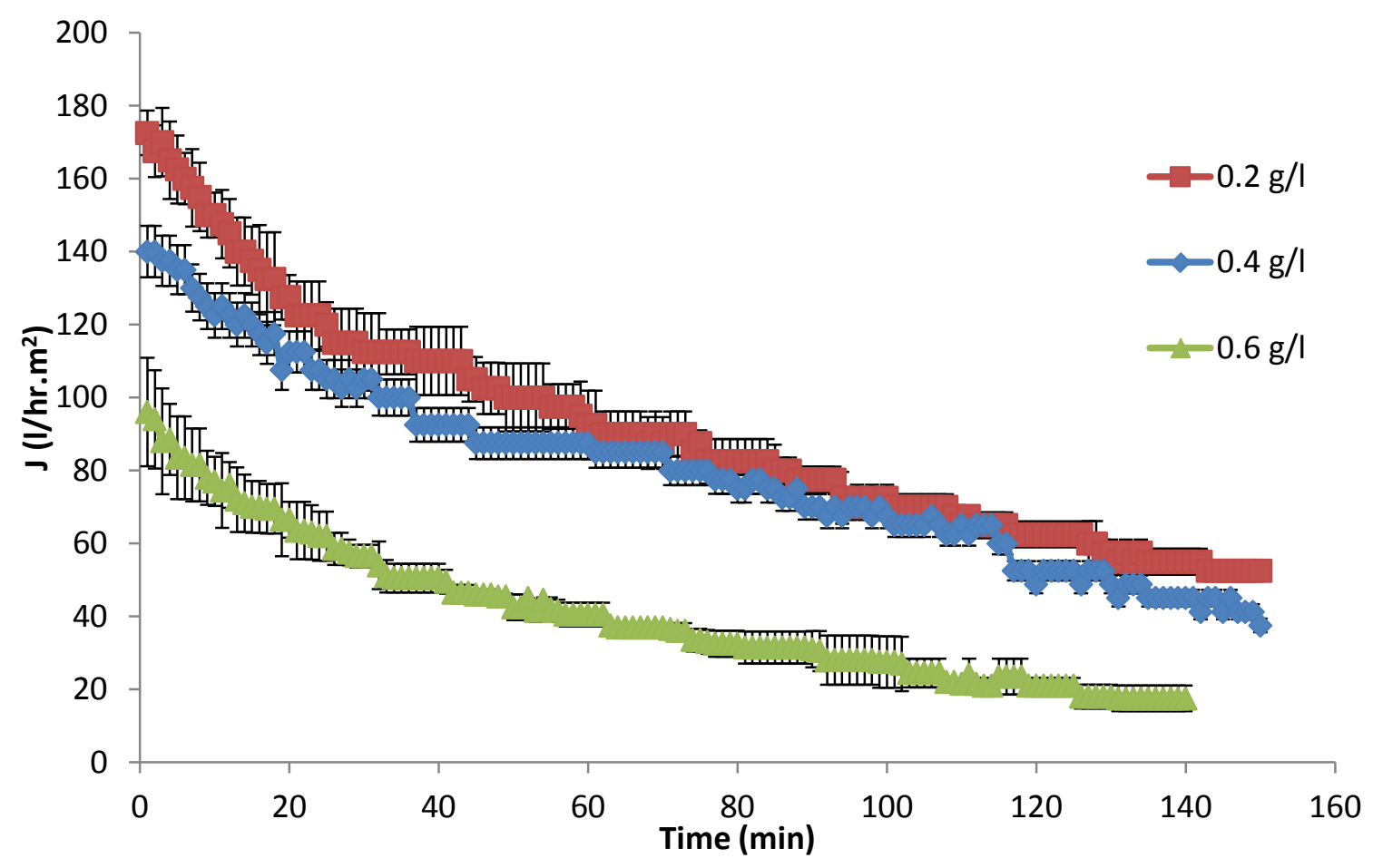

290 Figure 5 Effect of suspension concentrations of $0.2 \mathrm{~g} / \mathrm{l}, 0.4 \mathrm{~g} / \mathrm{l}$, and $0.6 \mathrm{~g} / \mathrm{l}$ on permeate flux 291 decline for circular crossflow module.

292 We investigated the influence of concentration of china clay particles on the flux decline in the 293 circular crossflow system and the results are shown in Figure 5. The cross flow velocities and 294 filtration pressure are kept the same for all the experiments. Generally, it can be seen from 295 Figure 5 that the permeate flux decreases with the increasing solids concentration of the feed 296 suspension. This observation is consistent with that of Hwang and Sz's (2011).

297 Scanning electron microscope (SEM) images of top surface of the membranes are obtained at 298 solids concentration of $0.2 \mathrm{~g} / \mathrm{l}$ and $0.6 \mathrm{~g} / \mathrm{l}$ in order to investigate the situation of membrane 299 fouling after the microfiltration process (Figure 6). At higher concentration, there is a tendency 300 for more china clay particles accumulated on the surface of the membrane which leads to the 301 formation of a cake layer. As seen from Figure 6, the higher the suspension concentration, the 302 thicker the cake layer is since china clay particles deposited on the membrane surface at fixed 303 suspension volume. The increasing thickness of the cake layer contributes to the resistance 304 which confirms the observation mentioned above. 


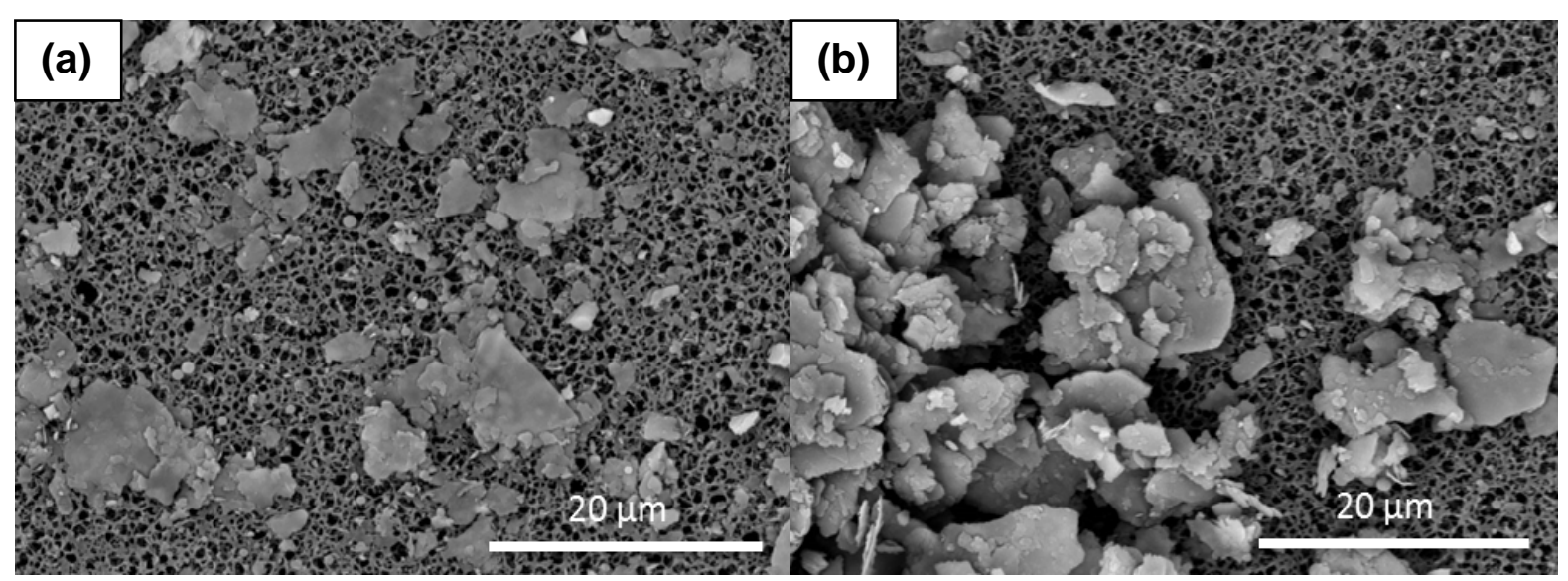

306 Figure 6 Scanning electron microscope (SEM) images of membrane surfaces after filtration

307 process at different concentrations: (a) $0.2 \mathrm{~g} / \mathrm{l}$, and (b) $0.6 \mathrm{~g} / \mathrm{l}$.

309 The typical impact of the filtration pressure on the flux decline is shown in Figure 7, which was 310 consistent with Hwang and Sz's (2011). However, the permeate fluxes also decrease more 311 rapidly with increasing filtration pressure. This phenomenon is very significant with the 312 microfiltration of large particles like the china clay particles used in the experiments (Tarleton 313 and Wakeman, 1994). Figure 7 shows that the permeate fluxes are directly proportional to the 314 filtration pressure.

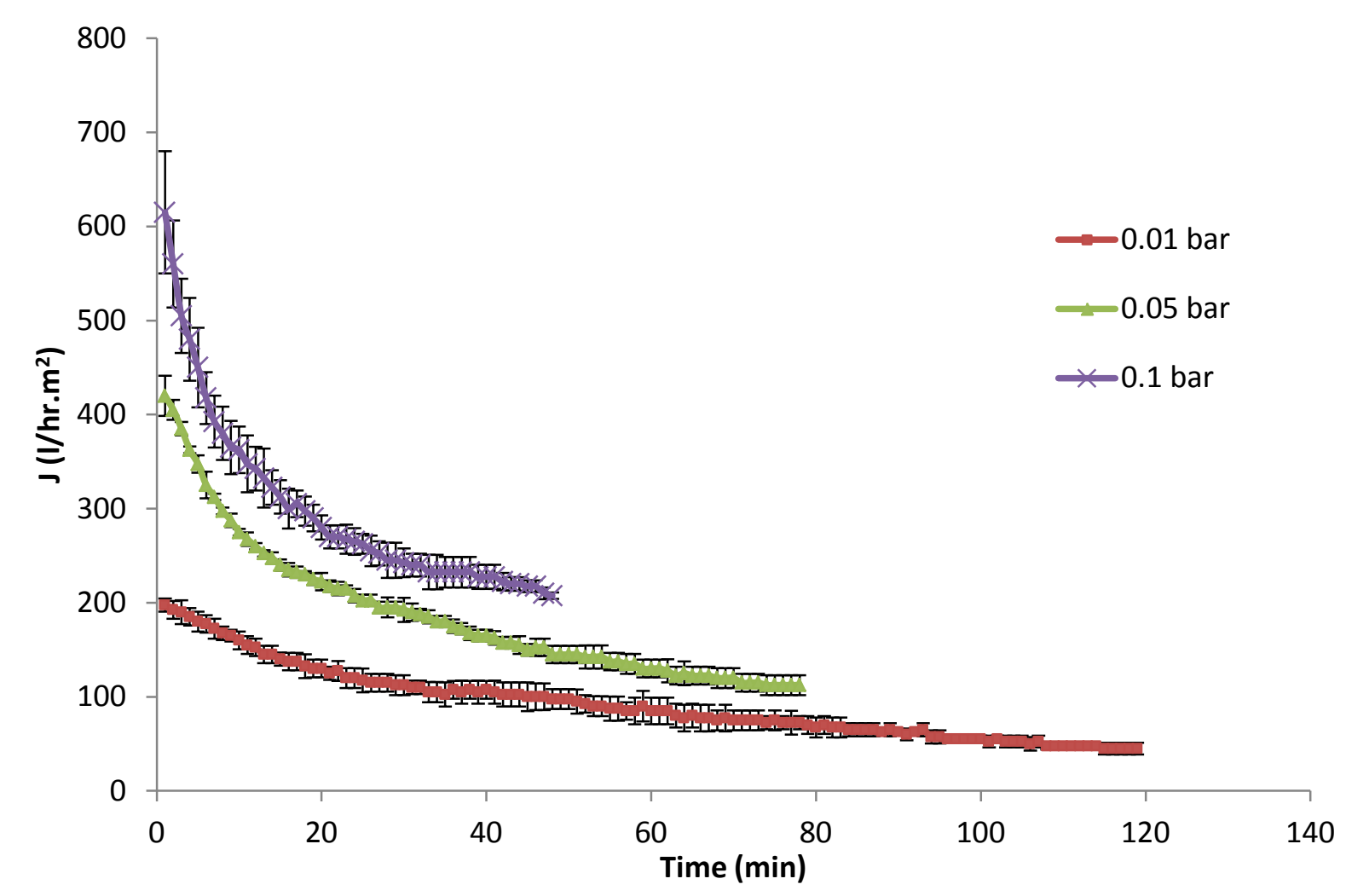

316 Figure 7 Effect of filtration pressures of 0.01 bar, 0.05 bar and 0.1 bar on permeate flux decline. 317 Suspension concentration is $0.4 \mathrm{~g} / \mathrm{l}$. 
318 In order to further verify the trends in terms of flux decline (Figure 7) caused by the change in the 319 filtration pressure, SEM images are collected for measuring the thickness of the cellulose ester 320 membrane samples after the filtration process. The thickness of the membrane is $150 \mu \mathrm{m}$ as 321 indicated by the manufacturer. As seen from Figure 8 different filtration pressures did not have 322 significant influence on the thickness of the membranes in the investigated range of 323 transmembrane pressures. The thicknesses are the same (about $150 \mu \mathrm{m}$ after the experiment) 324 which indicates that the membrane characterisations stay constant for each membrane 325 employed.
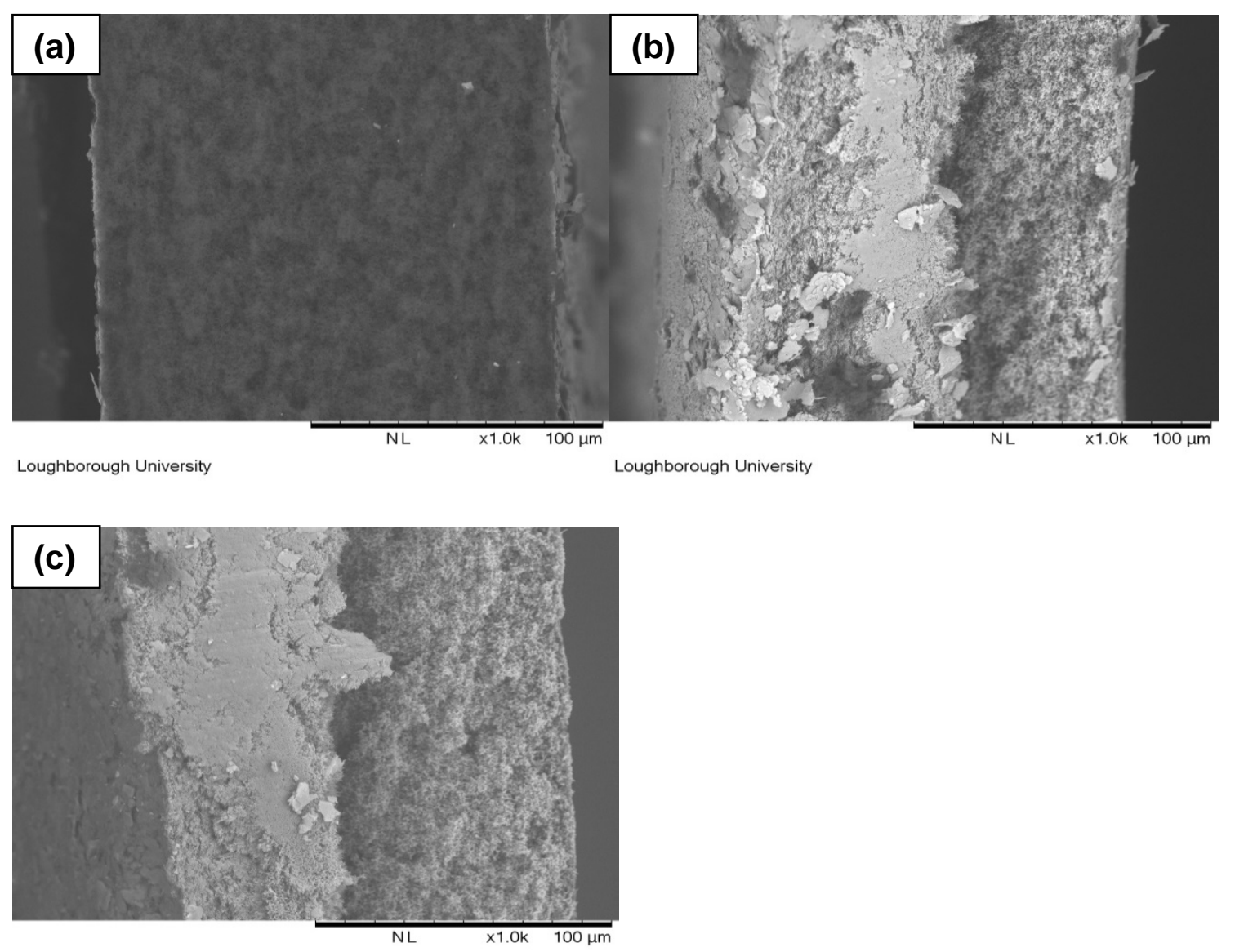

327 Loughborough University

328 Figure 8 Scanning electron microscope images of the cross section of each membrane after 329 filtration process at different filtration pressures: (a) 0.01bar, (b) 0.05bar, and (c) 0.1bar.

330 The decreased influence of Dean vortices was observed as filtration progressed due to rapid 331 solute build up and shear stress decreased the particle lift forces thus resulting in deposition of 332 solutes on membrane surface. Therefore, it would be very important to search for optimum 333 operating and hydrodynamic conditions, i.e. higher wall shear stress (high operating pressure, 334 greater than 0.1 bar) and dilute solute concentration might be desirable (less than $0.2 \mathrm{~g} / \mathrm{l}$ ), in 335 order to have maximum effect of Dean vortices. 
338 Energy consumption is an important aspect to consider the feasibility of an industrial application.

339 The energy consumption for both systems were calculated and compared at similar operating 340 conditions. According to Manno et al. (1998), the energy dissipated per unit volume of permeate,

$341 E$ can be calculated using the following formula:

$342 E=\left[Q / Q_{P} \Delta P_{I O}+\Delta P\right] / 3.6 \times 10^{6}$,

343 where $Q$ is the feed flow rate, $Q_{P}$ is the permeate flow rate, $\Delta P_{I O}$ is the pressure difference 344 between the inlet and outlet, and $\Delta P$ is the transmembrane pressure.

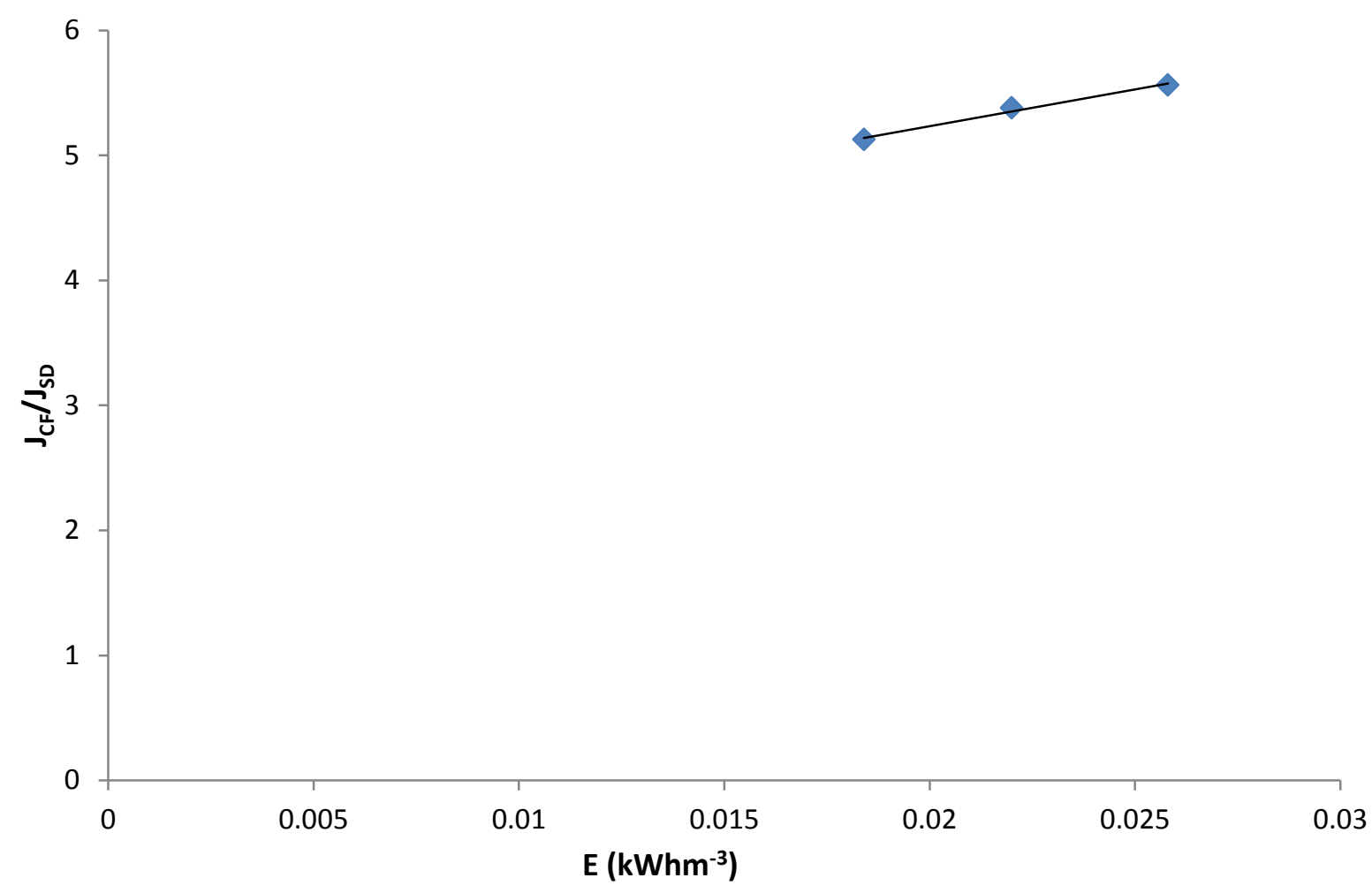

$\mathrm{E}\left(\mathrm{kWhm} \mathrm{m}^{-3}\right)$

346 Figure 9 Ratio of limiting flux in circular crossflow to stirred dead end as a function of dissipated 347 energy.

349 Figure 9 shows the limiting ratio (circular crossflow to stirred dead end) as a function of energy 350 dissipated. For the same energy rate, the limiting flux reached in circular crossflow is always 351 higher than stirred dead end. Observation on energy consumption by any modules with Dean 352 vortices effects was also made by Moulin et al. (1999) and Manno et al. (1998). They concluded 353 that the presence of Dean secondary flow even at fixed amount energy dissipated would result 354 in more permeation fluxes compared to other conventional modules. With regard to the energy 355 calculations both set-ups i.e. circular crossflow and stirred dead end operated at quite low 356 pressures ( 0.1 bar and below) for the filtration experiments, hence, it was predicted that the 357 amount of energy dissipated would be low as well. Also, the time required for the filtration 
experiment to complete at filtration pressure of 0.1 bar was less than 1 hour. Also, the system is scalable and the scalability of this analysis would be presented elsewhere.

\section{Conclusions}

Comparative study between stirred dead end and circular crossflow in microfiltration of china clay suspension was investigated. Comparison was made with respect to convective mass transfer coefficients, permeation and rejection rates, and energy consumption. Similar operating and hydrodynamic conditions were implemented. From our experimental data circular crossflow module was proven to perform better when compared to the stirred dead end system due to the higher mass transfer coefficients, higher permeation rates with lower energy consumption. The mass transfers gathered are comparable to studies previously done in vortex flow filtration and dead end flow filtration. The presence of Dean vortices in circular crossflow module promotes flow instabilities in the curved channel flow path which reduced concentration polarization effect during the filtration process. For the same energy cost, the limiting flux reached in circular crossflow is always higher than stirred dead end. Hence, it is proven that energy consumed was less for circular crossflow module than for stirred dead end module with higher permeation rates. From the study of hydrodynamics of both set-ups, the mass transfer coefficients of particles could be determined. Hence, it is proven to have significant advances in the practical and theoretical aspects of water science and technology as presented elsewhere by the authors.

\section{Acknowledgements}

The authors would like to thank Brunei Government for the PhD studentship granted to Norazanita Shamsuddin at Loughborough University.

\section{References}

Akay, G, and R.J Wakeman. "Crossflow microfiltration behaviour of a double-chain cationic surfactant dispersion in water-l. The effect of process and membrane characteristics on permeate flux and surfactant rejection." Chemical Engineering Science, 49(2), 1994: 271283.

Becht, N.O, D.J Malik, and E.S Tarleton. "Evaluation and comparison of protein ultrafiltration test results: Dead-end stirred cell compared with a cross-flow system." Separation and Purification Technology, 62, 2008: 228-239.

Belfort, G. Coiled membrane filtration system. US Patent Patent 5626758. 1997.

Belfort, G, P Mikulasek, J.M Pimbley, and K.Y Chung. "Diagnosis of membrane fouling using a rotating annular filter. 2. Dilute particle suspensions of known particle size." Journal of Membrane Science, 77(1), 1993: 23-39.

Blatt, W.F, A Dravid, A.S Michaels, and L Nelsen. "Solute polarization and cake formation in membrane ultrafiltration: causes, consequences, and control techniques." Membrane Science and Technology, 1970: 47-97. 
Bratby, J. Coagulation and Flocculation. London: Uplands press, 1980.

397

398

399

400

401

402

403

404

405

406

407

408

409

410

411

412

413

414

415

416

417

418

419

420

421

422

423

424

425

426

427

428

429

430

431

432

Brewster, D.B, P Grosberg, and A.H Nissan. "The stability of viscous flow between horizontal concentric cylinders." Proceedings of the Royal Society of London. Series A. Mathematical and Physical Sciences, 251, 1959: 76-91.

Brewster, M.E, K.Y Chung, and G Belfort. "Dean vortices with wall flux in a curved channel membrane system. 1. A new approach to membrane module design." Journal of Membrane Science, 81, 1993: 127-137.

Bubolz, M, M Wille, G Langer, and $U$ Werner. "The use of dean vortices for crossflow microfiltration: basic principles and further investigation." Separation and Purification Technology, 26(1), 2002: 81-89.

Charcosset, C. "Membrane processes in biotechnology: an overview." Biotechnology advances, 24(5), 2006: 482-492.

Chung, K.Y, and K.M Chang. "Fouling steps in the microfiltration of Kaolin suspension ." J. Ind. Eng. Chem., 7(4), 1991: 250-258.

Chung, K.Y, M.E Brewster, and G Belfort. "Dean vortices with wall flux in a curved channel membrane system. 2. The velocity field ." AIChE Journal, 42 , 1996: 347-358.

Chung, K.Y, R Bates, and G Belfort. "Dean vortices with wall flux in a curved channel membrane system. 4. Effect of vortices on permeation fluxes of suspensions in microporous membrane ." Journal of Membrane Science, 81 , 1993: 139-150.

Chung, K.Y, W.A Edelstein, and G Belfort. "Dean vortices with wall flux in a curved channel membrane system. 6. Two-dimensional resonance imaging of the velocity field in a curved impermeable silt." Journal of Membrane Science, 81 , 1993: 151-162.

Chung, K.Y, W.A Edelstein, and X Li. "Dean vortices in curved tube flow. 5. 3-D MRI and numerical analysis of the velocity field." AIChE Journal, 39 , 1993: 1592-1602.

Colton, C.K, L.W Henderson, C.A Ford, and M.J Lysaght. "Kinetics of hemodiafiltration. I. In vitro transport characteristics of a hollow-fiber blood ultrafilter." The Journal of laboratory and clinical medicine, 85(3), 1975: 355-371.

Costa, A.R, M Norberta de Pinho, and M Elimelech. "Mechanisms of colloidal natural organic matter fouling in ultrafiltration." Journal of Membrane Science, 281, 2006: 716-725.

Çulfaz, P.Z, M Haddad, M Wessling, and R.G.H Lammertink. "Fouling behavior of microstructured hollow fibers in cross-flow filtrations: Critical flux determination and direct visual observation of particle deposition." Journal of Membrane Science, 372(1), 2011: 210-218.

Cussler, E.L. Diffusion: mass transfer in fluid systems. Cambridge university press, 2009.

Dean, W.R. "Fluid motion in a curved channel." Proceedings of the Royal Society of London. London: Series A, Containing Papers of a Mathematical and Physical Character, 1928. 402-420. 
Einstein, A. "Über die von der molekularkinetischen Theorie der Wärme geforderte Bewegung von in ruhenden Flüssigkeiten suspendierten Teilchen." Annalen der Physik, 322(8), 1905: 549-560.

Gao, W, et al. "Membrane fouling control in ultrafiltration technology for drinking water production: A review." Desalination, 272(1), 2011: 1-8.

Gray, S.R, N Dow, J.D. Orbell, T Tran, and B.A Bolto. "The significance of interactions between organic compounds on low pressure membrane fouling." Water Science \& Technology, 64(3), 2011: 632-639.

Guo, W, H.H Ngo, and J Li. "A mini-review on membrane fouling." Bioresource technology, 122, 2012: 27-34.

Hwang, K.J, and P.Y Sz. "Membrane fouling mechanism and concentration effect in cross-flow microfiltration of BSA/dextran mixtures." Chemical Engineering Journal, 166(2), 2011: 669-677.

Jaffrin, M.Y. "Hydrodynamic techniques to enhance membrane filtration." Annual Review of Fluid Mechanics, 44, , 2012: 77-96.

Kaur, J, and G.P Agarwal. "Studies of protein transmission in thin channel flow module: the role of dean vortices for improving mass transfer." Journal of Membrane Science 196, 2002: $1-11$.

Kochkodan, V, D.J Johnson, and N Hilal. "Polymeric membranes: Surface modification for minimizing (bio) colloidal fouling." Advances in colloid and interface science, 206, 2014: 116-140.

Kosvintsev, S.R, G Gasparini, R.G Holdich, I.W Cumming, and M.T Stillwell. "Liquid-liquid membrane dispersion in a stirred cell with and without controlled shear." Industrial \& engineering chemistry research 44 (24), 2005: 9323-9330.

Kroner, $\mathrm{K} . \mathrm{H}$, and $\mathrm{V}$ Nissinen. "Dynamic filtration of microbial suspensions using an axially rotating filter." Journal of Membrane Science, 36, 1988: 85-100.

Madaeni, S.S, A Khorasani, M Asgharpour, S.A Ghoreshi, and M Lotfi. "Removal of mixtures of viruses using microfiltration membrane." Desalination and Water Treatment, 51(22-24), 2013: 4313-4322.

Mallubhotla, H, and G Belfort. "Flux enhancement during Dean vortices microfiltration. 8. Further diagnostics." Journal of Membrane Science, 125 , 1997: 75-91.

Mallubhotla, H, E Numes, and G Belfort. "Microfiltration of yeast suspensions with self-cleaning spiral vortices: possibilities for a new membrane module design." Biotechnolgy and Bioengineering, 48, 1995: 375-385.

Mallubhotla, H, S Luque, and G Belfort. "Membrane filtration with self-cleaning spiral vortices." Euromembrane '97, Progress in Membrane Science and Technology. University of Twente, The Netherlands: A.J.B. Kemperman, G.H. Koops (Eds.), 1997. 385-387.

Manno, P, P Moulin, J.C Rouch, M Clifton, and P Aptel. "Mass transfer improvement in helically wound hollow fibre ultrafiltration modules Yeast suspensions." Separation and Purification Technology, 14, 1998: 175-182. 
Mehta, A, and A.L Zydney. "Effect of membrane charge on flow and protein transport during ultrafiltration." Biotechnology Progress 22(2), 2006: 484-492.

Muller, C, G Agarwal, T Melin, and T Wintgens. "Study of ultrafiltration of a single and binary protein solution in a thin spiral channel module ." Journal of Membrane Science 227, 2003: 51-69.

478 Nunge, R.J, and L.R Adams. "Reverse osmosis in laminar flow through curved tubes." Desalination, 13, 1971: 17-36.

Park, J.Y, C.K Choi, and J.J Kim. "A study on dynamic separation of silica slurry using a rotating membrane filter 1. Experiments and filtrate fluxes." Journal of Membrane Science, 97, 1994: 263-273.

Shamsuddin, N, D.B Das, and V.M Starov. "Membrane-based point-of-use water treatment (PoUWT) system in emergency situations." Separation \& Purification Reviews DOI:10.1080/15422119.2014.973967 (in press), 2014.

Song, L, and M Elimelech. "Theory of concentration polarization in crossflow filtration." J. Chem. Soc., Faraday Trans., 91(19), 1995: 3389-3398.

488 Srinivasan, S, and C Tien. "Reverse osmosis in a curved tubular membrane duct." Desalination, 489 9, 1971: 127-139.

Strathmann, H, L Giorno, and E Drioli. Introduction to membrane science and technology. Wiley491 VCH Verlag \& Company, 2011.

492 Tarleton, E.S, and R.J Wakeman. "Understanding flux decline in crossflow microfiltration: Part 1. 493 Effects of particle/pore size." Trans IChemE, 71(A), 1993: 399-410.

494 Tarleton, E.S, and R.J Wakeman. "Understanding flux decline in crossflow microfiltration: Part 2. 495 Effects of process parameters." Trans IChemE, 72(A), 1994: 431-440.

496 WHO. Guidelines for Drinking water Quality (Fourth Edition). 2012. 497

Winzeler, H.B, and G Belfort. "Enhanced performance for pressure-driven membrane processes:

500 Zydney, A.L, and C.K Colton. "A concentration polarization model for the filtrate flux in cross-flow 501 microfiltration of particulate suspensions." Chemical Engineering Communications, 47(1502 3), 1986: 1-21. 